\title{
Inhibition of the endosymbiont "Candidatus Midichloria mitochondrii" during 16S rRNA gene profiling reveals potential pathogens in Ixodes ticks from Australia
}

Alexander W. Gofton ${ }^{1}$, Charlotte L. Oskam', Nathan Lo ${ }^{2}$, Tiziana Beninati ${ }^{3}$, Heng Wei ${ }^{2}$, Victoria McCarl ${ }^{2}$, Dáithí C. Murray ${ }^{4}$, Andrea Paparini', Telleasha L. Greay ${ }^{1}$, Andrew J. Holmes ${ }^{5}$, Michael Bunce ${ }^{4}$, Una Ryan ${ }^{1}$ and Peter Irwin ${ }^{*}$

\begin{abstract}
Background: The Australian paralysis tick (Ixodes holocyclus) is of significant medical and veterinary importance as a cause of dermatological and neurological disease, yet there is currently limited information about the bacterial communities harboured by these ticks and the risk of infectious disease transmission to humans and domestic animals. Ongoing controversy about the presence of Borrelia burgdorferi sensu lato (the aetiological agent of Lyme disease) in Australia increases the need to accurately identify and characterise bacteria harboured by I. holocyclus ticks.

Methods: Universal PCR primers were used to amplify the V1-2 hyper-variable region of bacterial $16 \mathrm{~S}$ rRNA genes present in DNA samples from I. holocyclus and I. ricinus ticks, collected in Australia and Germany respectively. The 165 amplicons were purified, sequenced on the lon Torrent platform, and analysed in USEARCH, QIIME, and BLAST to assign genus and species-level taxonomy. Initial analysis of I. holocyclus and I. ricinus identified that $>95 \%$ of the $16 \mathrm{~S}$ sequences recovered belonged to the tick intracellular endosymbiont "Candidatus Midichloria mitochondrii" (CMM). A CMM-specific blocking primer was designed that decreased CMM sequences by approximately $96 \%$ in both tick species and significantly increased the total detectable bacterial diversity, allowing identification of medically important bacterial pathogens that were previously masked by CMM.

Results: Borrelia burgdorferi sensu lato was identified in German I. ricinus, but not in Australian I. holocyclus ticks. However, bacteria of medical significance were detected in I. holocyclus ticks, including a Borrelia relapsing fever group sp., Bartonella henselae, novel "Candidatus Neoehrlichia" spp., Clostridium histolyticum, Rickettsia spp., and Leptospira inadai.
\end{abstract}

Conclusions: Abundant bacterial endosymbionts, such as CMM, limit the effectiveness of next-generation $16 \mathrm{~S}$ bacterial community profiling in arthropods by masking less abundant bacteria, including pathogens. Specific blocking primers that inhibit endosymbiont 165 amplification during PCR are an effective way of reducing this limitation. Here, this strategy provided the first evidence of a relapsing fever Borrelia sp. and of novel "Candidatus Neoehrlichia" spp. in Australia. Our results raise new questions about tick-borne pathogens in I. holocyclus ticks.

Keywords: Tick, Vector-borne disease, Zoonoses, Metagenomics, $16 \mathrm{~S}$ community profiling, Ixodes holocyclus, Ixodes ricinus, Candidatus Midichloria, Borrelia, Candidatus Neoehrlichia

\footnotetext{
*Correspondence: p.irwin@murdoch.edu.au

${ }^{1}$ Vector and Water-Borne Pathogen Research Laboratory, School of Veterinary

and Life Sciences, Murdoch University, Perth, Western Australia, Australia

Full list of author information is available at the end of the article
} 


\section{Background}

Ticks are the second most important vector of pathogens to humans after mosquitoes and the chief cause of vector-borne diseases in domestic animals and wildlife [1-3]. Ticks also vector the greatest diversity of pathogenic microorganisms of any haematophagous arthropod, including members of the bacterial genera Anaplasma [4], Bartonella [5], Borrelia [6], Ehrlichia [7], Francisella [8], Rickettsia [9], and "Candidatus Neoehrlichia" [10]. Furthermore, bacterial co-infections in ticks are common and provide diagnostic and therapeutic challenges for medical and veterinary practitioners [11-13]. In Europe, North America, and Australia the incidence of tick-borne diseases is rising due to a combination of factors including perturbation in climate, increasing populations and movement of humans and domestic animals, and increased human encroachment into tick habitats [14].

In Australia there is a long-standing controversy concerning the presence of Lyme disease and its aetiological agents, Borrelia burgdorferi sensu lato. First reported in the 1980s [15, 16], intensive efforts to determine the aetiological agent of Australian "Lyme-like" illness found no evidence for B. burgdorferi sensu lato in ticks or wildlife $[17,18]$, yet numerous victims of tick bites continue to present with Lyme-like symptoms in Australia [19]. Thus there is a pressing need to apply contemporary next-generation sequencing (NGS) techniques to better understand bacterial pathogens harboured in Australian ticks.

In Australia I. holocyclus is the most important tick species from both a medical and veterinary perspective $[20,21]$. Its enzootic range is limited to a narrow strip along Australia's eastern seaboard that extends several thousand kilometres from Cape York to eastern Victoria, and includes most of Australia's most densely populated regions [22]. Ixodes holocyclus is commonly found on domestic animals in which it causes life-threatening paralysis. Ixodes holocyclus is also the most common tick found on people in its range and impacts human health by causing weakness, paralysis, allergic reactions, and is a vector for the spotted fever pathogens Rickettsia australis and $R$. honei [23].

Together with known vector-borne pathogens, ticks also harbour closely related endosymbiotic bacteria such as Coxiella spp. [24-26], Francisella spp. [27-29], Wolbachia spp. [30, 31], Rickettsia spp. [32-35], and the recently discovered "Candidatus Midichloria mitochondrii" (CMM) [36-39]. These bacterial endosymbionts often dominate the microbial population within their arthropod hosts and can affect the transmission dynamics of pathogenic species [40-42].

$\mathrm{CMM}$ is an intracellular endosymbiont that was first discovered in the European sheep tick Ixodes ricinus
[36] but has since been detected in other ticks including I. holocyclus [37, 43-47], as well as tabanid flies [48], bed bugs [49], and mites [50]. In ticks, CMM resides in high numbers in female reproductive tissues and is transmitted to all offspring where it infects $100 \%$ of larvae, nymphs, and females [36, 51]. Male I. holocyclus ticks also appear to inherit and harbour CMM, however, I. ricinus males fail to establish stable CMM populations $[36,38,51]$. In addition to this, CMM is found in I. ricinus salivary glands from where it is introduced during feeding to vertebrate hosts, including humans [52, 53]. However, the consequences of CMM infection in vertebrate hosts, if any, are unknown [52].

Next-generation sequencing and bioinformatics advances have greatly increased our ability to accurately identify trace amounts of DNA in highly heterogeneous samples, making them excellent tools for molecular epidemiological studies of pathogens that may be present in low abundance. In particular, the application of $16 \mathrm{~S}$ rRNA gene (hereafter referred to as 16S) community profiling has been particularly successful for characterising bacterial assemblages from a wide variety of sources, including ticks [30, 54-62]. With this methodology, a short region (100-500 bp) of the $16 \mathrm{~S}$ gene is amplified using PCR primers that bind to orthologous regions either end of a hyper-variable region of the gene. Because the primers bind to orthologous regions of the $16 \mathrm{~S}$ gene numerous bacterial taxa within a heterogeneous sample can be targeted simultaneously, and the hyper-variable region proximal to the primers permits taxonomic discrimination of those taxa $[63,64]$.

A limitation of $16 \mathrm{~S}$ community profiling in ticks is that a high proportion of sequences generated during PCR will belong to bacterial endosymbionts [40]. These overabundant endosymbiont $16 \mathrm{~S}$ sequences can mask the presence of less abundant bacterial $16 \mathrm{~S}$ sequences including pathogens, resulting in biased results and a decreased detected bacterial diversity. This limitation can be overcome to some extent by deeper sequencing to increase detection of low abundant sequences. However, this approach fails to address the source of the problem and is costly, making it difficult to study a large number of samples. In addition, various factors such as biases in PCR amplification efficiency and inter-specific variation of the $16 \mathrm{~S}$ copy number are known to skew the measured proportion of NGS reads, and limits the use of sequence abundance to infer actual bacterial abundance in the original sample $[65,66]$.

As part of an ongoing study into tick-borne diseases in Australia, we developed a primer that inhibits amplification of CMM $16 \mathrm{~S}$ sequences, enabling us to identify other less abundant bacteria in I. holocyclus and I. ricinus. This approach has provided insights into the bacterial microbiome of $I$. holocyclus and is readily applicable 
to other arthropod vectors of plant and animal diseases where overabundant species prove problematic to the identification of important taxa.

\section{Methods}

\section{Sample collection}

A total of 196 individual specimens of $I$. holocyclus, were collected from mammalian $(n=85)$ and avian $(n=2)$ hosts, and from the environment $(n=109)$ in various locations in New South Wales, Australia, between 2004 and 2014 (Table 1). All host-seeking I. holocyclus ticks were collected by flagging, using standard techniques [67], and either preserved frozen, stored in $70 \%$ ethanol, or used immediately. In addition, 20 nymph and ten female I. ricinus ticks were collected by flagging in suburban parks in the cities of Freising and Leipzig, Germany, in 2013, and were immediately placed in $70 \%$ ethanol and shipped to Murdoch University. All ticks were identified morphologically using standard keys $[68,69]$.

\section{Ethics statement}

This research complies with the Australian Code for the Responsible Conduct of Research, 2007 and the Australian Code for the Care and Use of Animals for Scientific Purposes, 2013. Removal of ticks from animal hosts was approved by the Murdoch University Animal Ethics Committee; collection from domestic animals $(n=35)$ and wildlife species $(n=26)$ was opportunistic, from individuals that were presented to veterinarians, or were dead as a result of unrelated accident or injury. Ticks $(n=26)$ were removed from humans by the person themselves or by medical professionals during outpatient treatment.

\section{DNA extraction}

Total genomic DNA from individual ticks was extracted using the Qiagen DNeasy Blood and Tissue Kit

Table 1 Ixodes holocyclus and I. ricinus ticks collected from different hosts and the environment

\begin{tabular}{lll}
\hline Tick Instar or Sex & $\begin{array}{l}\text { Number of } \\
\text { ticks }\end{array}$ & Hosts or Questing (number of ticks) \\
\hline $\begin{array}{l}\text { Ixodes holocyclus } \\
\text { Nymph }\end{array}$ & 196 & Questing (15) \\
Male & 41 & $\begin{array}{l}\text { Questing (41) } \\
\text { Bos taurus (4), Canis familiaris (26), } \\
\text { Female }\end{array}$ \\
& 140 & $\begin{array}{l}\text { Corvus coronoides (1), Cracticus tibicen (1), } \\
\text { Echidna (Family: Tachyglossidae) (1), } \\
\text { Felis catus (5), Homo sapiens (26), } \\
\text { Macropus spp. (9), Trichosurus vulpecula (14), } \\
\text { Questing (53). }\end{array}$ \\
Ixodes ricinus & 30 & $\begin{array}{l}\text { Questing (20) } \\
\text { Nymph }\end{array}$ \\
Female & 20 & Questing (10) \\
\hline
\end{tabular}

(Qiagen, Germany) following the manufacturer's recommendations (Qiagen Supplementary Protocol: Purification of total DNA from insects). Before extraction, individual ticks were surface sterilised in $10 \%$ sodium hypochlorite, washed in $70 \%$ ethanol and DNA-free PBS, frozen in liquid nitrogen for $1 \mathrm{~min}$, and homogenised with $5 \mathrm{~mm}$ steel beads in a Tissue Lyser LT (Qiagen, Germany) for $1 \mathrm{~min}$ at $40 \mathrm{~Hz}$. DNA-free equipment and tubes were used for each step and equipment was decontaminated between samples with DNAaway (Life Technologies, USA). Extraction reagent blanks were performed in parallel with all DNA extractions in order to determine background bacterial populations (one extraction reagent blank for every 23 samples). To prevent potential cross-contamination by known I. ricinus pathogens, DNA extractions from these ticks were performed in a separate laboratory to I. holocyclus DNA extractions.

\section{Blocking primer design}

In pilot $16 \mathrm{~S}$ community profiling experiments, over $95 \%$ of the sequences generated from each sample, from both I. holocyclus and I. ricinus ticks, belonged to CMM regardless of the sequencing depth, PCR primers, or sequencing platform used (data not shown). To inhibit amplification of these overabundant sequences during PCR, we developed a CMM-specific blocking primer (MidBlocker) [70] to be used in conjunction with the $16 \mathrm{~S}$ universal primers 27F-Y (Fig. 1) and 338R (5'-TGC TGCCTCCCGTAGGAGT-3') that amplify the V1-V2 16S region [71]. The MidBlocker primer was designed from an alignment of 107 partial 16S sequences including known tick-borne pathogens and endosymbionts, ubiquitous environmental bacteria, and CMM (Fig. 1). The 5' end of the MidBlocker primer has a 7 bp overlap with the 3' end of the 27F-Y primer, extends $15 \mathrm{bp}$ downstream of the 27F-Y primer-binding site, and terminates polymerase elongation due to a $\mathrm{C} 3$ spacer at the 3' end of the primer (Fig. 1). In silico analysis (not shown) suggests that the MidBlocker primer is specific to CMM and will not modulate the binding of the 27F-Y primer to other closely related Rickettsiaceae and Anaplasmataceae.

\section{Validation of the MidBlocker primer}

Total DNA from host-seeking female I. holocyclus $(n=10)$ and $I$. ricinus $(n=10)$ were amplified by qPCR using the 27F-Y and 338R primers with and without $10 \mu \mathrm{M}$ of MidBlocker primer. Different concentrations (2-14 $\mu \mathrm{M})$ of the MidBlocker primer were trialled in pilot experiments on a subset of samples (data not shown). PCR conditions, fusion-primer architecture, semiconductor sequencing, and sequence analysis were the same as described below. Nonparametric Mann-Whitney U-tests were performed in Quantitative Insights Into Microbial 


\begin{aligned} Name (NCBI accession) & Sequence (5'-3') \\ \hline 27F-Y Primer (This study) & AGAGTTTGATCCTGGCTYAG \\ MidBlocker Primer (This study) & GGCTYAGAGTGAACGCTGGCGG/C3/ \\ Candidatus Midichloria mitochondrii (CP002130) & AGAGTTTGATCCTGGCTCAGAGTGAACGCTGGCGG \\ Borrelia burgdorferi (B31_30245) & AGAGTTTGATCCTGGCTTAGAACTAACGCTGGCAG \\ Borrelia afzelii (CP009212) & AGAGTTTGATCCTGGCTTAGAACTAACGCTGGCAG \\ Borrelia duttonii (AF107364) & AGAGTTTGATCCTGGCTTAGAACTAACGCTGGCAG \\ Rickettsia rickettsia (CP000766) & AGAGTTTGATCCTGGCTCAGAACGAAGCTATCGG \\ Bartonella henselae (AJ223780) & AGAGTTTGATCATGGCTCAGAACGAACGCTGGCG \\ Ehrlichia chaffeensis (CP007480) & AGAGTTTGATCCTGGCTCAGAACGAAGCTGGCGG \\ Anaplasma phagocytophilum (CP006618) & AGAGTTTGATCCTGGCTCAGAACGACGCTGGCGG \end{aligned}

Fig. 1 Alignment of partial $16 \mathrm{~S}$ rDNA sequences and the 27F-Y and MidBlocker primers. Alignment includes partial $16 \mathrm{~S}$ sequences of seven tick-borne bacterial pathogens and "Candidatus M. mitochondrii" with the 27F-Y and MidBlocker primers showing mismatches that allow specific blocking of "Candidatus M. mitochondrii"

Ecology (QIIME) [72] to determine the significance of differences in bacterial diversity between samples amplified with and without MidBlocker; significance was set at $p<0.05$ (Mann-Whitney U-Test).

\section{$16 S$ community profiling qPCR}

The primers 27F-Y and 338R amplified the $16 \mathrm{~S} \mathrm{V1-2}$ hyper-variable regions (250-320 bp) [73] in I. holocyclus and $I$. ricinus DNA samples. 27F-Y and 388R primers also incorporated a six to eight base pair multiplex identifier (MID) sequence together with Ion Torrent sequencing adapters A and P1 (Life Technologies, USA). Each sample was amplified with primers containing a unique combination of forward and reverse MID sequences to allow multiplex sequencing and discrimination of sequences to samples in downstream analysis. All community profiling qPCRs were carried out in duplicate in $25 \mu \mathrm{l}$ reactions containing $1 \times \mathrm{PCR}$ buffer $(5$ prime, Germany), $2 \mathrm{mM} \mathrm{MgCl}_{2}$ (5 Prime, Germany), $0.25 \mathrm{mM}$ dNTPs (Fisher Biotech, Australia), $0.01 \mathrm{mg}$ BSA (Fisher Biotech, Australia), $0.4 \mu \mathrm{M}$ of each 27F-Y and 338R primer, $10 \mu \mathrm{M}$ of MidBlocker, $0.12 \times$ SYBR Green (Life Technologies, USA), 1 U of Perfect Taq Polymerase (5 Prime, Germany), $1 \times$ ROX dye (Life Technologies, USA), and $2 \mu \mathrm{l}$ of DNA (1-100 ng/ $\mu \mathrm{l})$. No-template control reactions and extraction reagent blank controls were included in every qPCR run and were incorporated in the sequencing libraries. All PCR amplifications were performed on a Step-One real-time qPCR machine (Applied Biosystems, USA) with the following thermal conditions: initial denaturation at $95^{\circ} \mathrm{C}$ for 5 min followed by 35 cycles of denaturation at $95{ }^{\circ} \mathrm{C}(30 \mathrm{~s})$, annealing at $62{ }^{\circ} \mathrm{C}(30 \mathrm{~s})$, and extension at $72{ }^{\circ} \mathrm{C}(45 \mathrm{~s})$. Thermocycling was followed by a melt curve and final extension at $72{ }^{\circ} \mathrm{C}$ for $10 \mathrm{~min}$.

\section{Library preparation and NGS}

$16 \mathrm{~S}$ amplicons from all samples and controls were pooled into one of four sequencing libraries in equimolar amounts. Amplicon libraries were then purified twice using 1.2 volumes of Agencourt Ampure XP beads (Agilent Technologies, USA) and quantified by qPCR using a known concentration of a serially diluted 152 bp synthetic oligonucleotide as a standard. qPCR reactions contained 1X Power Syber Green mastermix (Life Technologies, USA), $0.4 \mu \mathrm{M}$ Ion Torrent primers A and P1, and $2 \mu \mathrm{l}$ DNA template, and were run with the following thermal conditions: initial denaturation at $95{ }^{\circ} \mathrm{C}$ for $5 \mathrm{~min}$ followed by 30 cycles of denaturation at $95{ }^{\circ} \mathrm{C}$ (30 s), annealing and extension at $60^{\circ} \mathrm{C}$ (45 s). Templating emulsion PCR and enrichment were performed according to the manufacturer's recommendations on the One-Touch 2 and One-Touch ES instruments (Life Technologies, USA). Sequencing was performed on an Ion Torrent PGM (Life Technologies, USA) using 400 bp chemistry and 316-V2 semiconductor chips, following the manufacturer's recommendations.

\section{Sequence processing and analysis}

Sequences were first processed in Geneious 8.0.4 [74] by retaining only reads with perfect $27 \mathrm{~F}-\mathrm{Y}$ and $338 \mathrm{R}$ primers and MID sequences (no mismatches allowed). Sequences were then de-multiplexed into individual samples based on their unique combination MID sequences. Primer sequences and distal bases were trimmed from each read, and reads shorter than the minimum reported length of the amplicon ( $<250 \mathrm{bp})$ were discarded. Remaining reads were quality filtered using USEARCH [75], allowing only reads with $\mathrm{a}<1 \%$ error rate to remain and singletons were removed on a per-sample basis. In order to identify bacterial genera present in samples operational taxonomic units (OTUs) were selected by clustering sequences at $97 \%$ similarity with the UPARSE algorithm [76]. OTUs were checked against the ChimeraSlayer Gold reference database with the UCHIME algorithm [77] to ensure OTUs were not the result of chimeric reads. Genus level taxonomy was assigned to OTUs against the GreenGenes $16 \mathrm{~S}$ database (August 2013 release) [78] in QIIME 1.8.0 [72] using the UCLUST algorithm [75] with default parameters. Only OTUs assigned to the genus level were used for further analysis. Bacterial genera that were identified in extraction reagent blanks and no-template controls were 
removed from the dataset to eliminate background bacterial sequences.

$16 \mathrm{~S}$ sequences from genera that contained known tickborne pathogens, known tick endosymbionts, or medically important bacteria that have not previously been associated with ticks, were compared against the NCBI GenBank Nucleotide database using BLAST [79] in an attempt to resolve species level taxonomy. Sequences were only assigned to a species if the query sequence matched only one species-specific reference sequence with a pairwise identity match $\geq 99 \%$ with $\geq 99 \%$ query coverage.

Sequences from the genera Borrelia, and "Candidatus Neoehrlichia" in this study were aligned with $16 \mathrm{~S}$ sequences from known members retrieved from GenBank using the Geneious alignment tool [74] and refined with MUSCLE [80]. Alignments were trimmed to match the length sequences obtained in this study. Borrelia alignment contained 27 members with 313 bp sequences including gaps and the "Candidatus Neoehrlichia" alignment contained 43 members with 309 bp sequences including gaps. Neighbour-joining phylogenetic trees were constructed from these alignments in Geneious [74] using the Tamura-Nei genetic distance model and resampling 1000 bootstrap replicates. "Borrelia" and "Candidatus Neoehrlichia" sequences from "I. holocyclus" ticks used for phylogenetic reconstructions were deposited in GenBank (accessions KT203914-6).

\section{Results}

\section{Validation of blocking primer}

Comparison of unique sequences recovered from PCR amplification with or without the MidBlocker primer revealed 46,698 vs. 14,154 sequences for I. holocyclus and 30,689 vs. 12,723 sequences for I. ricinus, respectively. Ixodes holocyclus and I. ricinus samples amplified without the MidBlocker primer contained a total of $98.2 \%$ and $99.6 \%$ CMM sequences respectively, while amplification with the MidBlocker primer decreased the number of CMM sequences to a total of only $2.3 \%$ and $3.6 \%$ of the reads respectively. Six of ten I. holocyclus samples and four of ten I. ricinus samples still contained CMM >sequences after amplification with the MidBlocker primer, however, these sequences comprised $<4 \%$ of sequences in each of these samples.

Consequent to the blocking step, all samples had a significantly higher taxonomic diversity when amplified with the MidBlocker primer than when amplified without the MidBlocker primer $(p<0.05$; Mann-Whitney U-Test). Amplification without the MidBlocker primer resulted in the detection of 32 and 14 bacterial genera in I. holocyclus and $I$. ricinus samples respectively, while inhibition of CMM 16S sequences resulted in the detection of 103 and 89 additional bacterial genera in I. holocyclus and I. ricinus samples respectively (Fig. 2). Furthermore, the MidBlocker primer did not appear to inhibit the amplification of other Rickettsiales closely related to CMM, as confirmed by the identification of members of the closely related Rickettsia and "Candidatus Neoehrlichia" genus in I. holocyclus and I. ricinus samples amplified with the MidBlocker primer.

\section{Bacterial pathogens in I. holocyclus and I. ricinus ticks}

After sequence processing, a total of 2,441,958 and 412,130 sequences were generated for I. holocyclus and I. ricinus ticks, respectively. Sixty-five bacterial genera were detected in extraction reagent and no-template controls, of which 28 were also present in at least one tick sample (Additional file 1). These genera were all associated with ubiquitous environmental and commensal bacteria and were subtracted from samples in order to eliminate potential environmental contaminants from the dataset. After removing background taxa a total of 199 and 95 bacterial genera were identified in I. holocyclus and I. ricinus samples, respectively (Additional files 2 and 3). Most bacteria identified were environmental and free-living bacteria often associated with soil and leaf-litter environments, characteristic of tick habitats. CMM was still the most common bacterium identified in I. holocyclus ticks (75.5\%) and the second most common in I. ricinus ticks (70 \%) after Rickettsiella spp. However, CMM sequences comprised an average of only $6.8 \%$ and $4.3 \%$ of sequences per sample for I. holocyclus and I. ricinus, respectively. Six genera of medical importance were found in tick samples including tickborne pathogens in the genera Anaplasma, Bartonella, Borrelia, "Candidatus Neoehrlichia", and Rickettsia, and the free-living pathogens Leptospira and Clostridium.

Bartonella henselae was identified with $100 \%$ sequence similarity to multiple known reference sequences [GenBank: AJ223779, HG726042, HG969191, JN646651] in one female $I$. holocyclus removed from a domestic cat. Additionally, a second Bartonella sp. was identified from a female I. holocyclus removed from a human. Bartonella sequences in this sample had multiple $>99 \%$ matches to three Bartonella species B. coopersplainsensis, B. australis, and B. rattaustraliani [GenBank: EU111759, DQ538394, EU111751]; species reported to date only in native Australian wildlife. Bartonella species were not identified in any $I$. ricinus ticks.

Borrelia $16 \mathrm{~S}$ sequences were obtained from ten questing I. ricinus ticks and a single I. holocyclus tick removed from a wild Echidna (Tachyglossidae sp.). Borrelia sequences derived from the I. holocyclus tick had 100 $\%$ sequence similarity, and clustered with high bootstrap confidence $(91.1 \%)$ into a group of pathogenic relapsing fever Borrelia species including B. duttonii, B. recurrentis, B. parkeri, and B. crocidurae (Fig. 3). Borrelia $16 \mathrm{~S}$ sequences derived from one $I$. ricinus tick clustered with high bootstrap confidence $(90.2 \%)$ with 

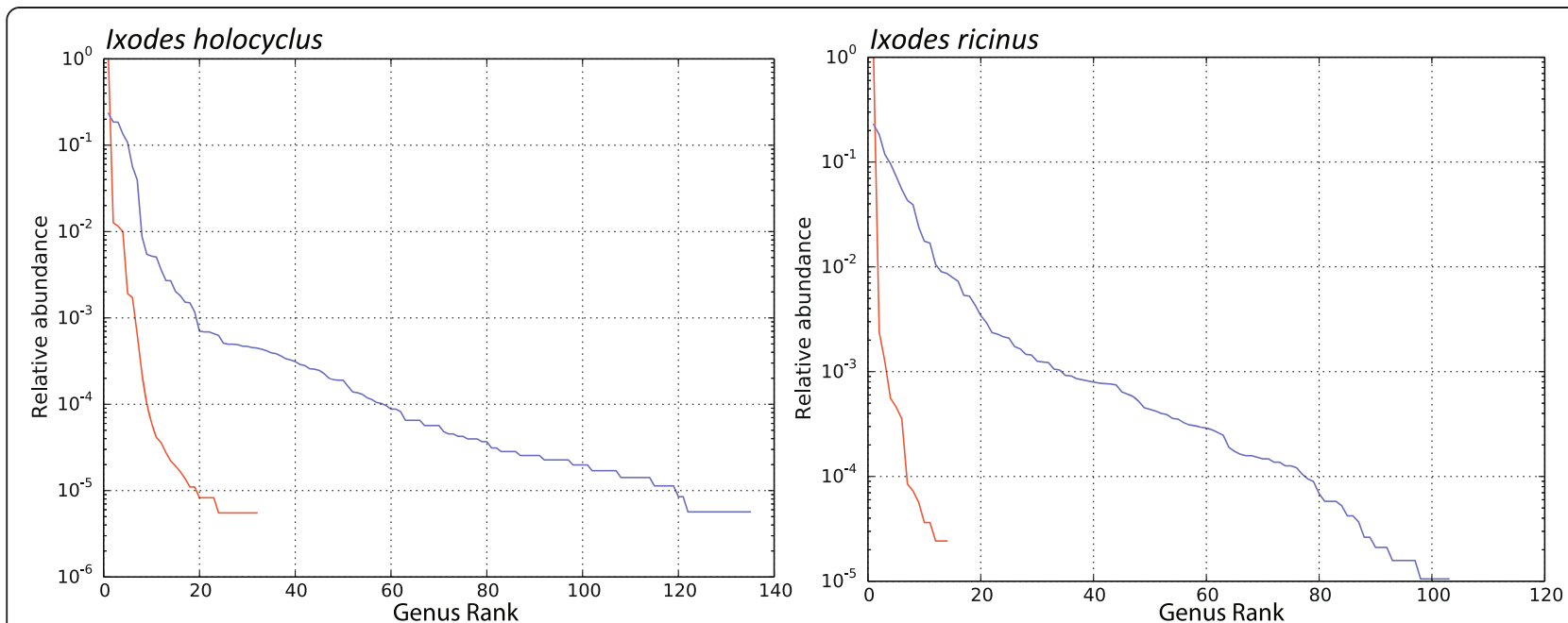

Fig. 2 Rank abundance plots of bacterial genera identified with and without blocking. The ranked relative abundance of bacterial genera identified in 10 I. holocyclus and 10 I. ricinus ticks when amplified with (blue lines) and without (red lines) the MidBlocker primer. X-axis represents the number of bacterial genera identified

the pathogenic relapsing fever Borrelia spp. B. miyamotoi and B. lonestari, with $99.3 \%$ and $97.7 \%$ sequence similarity respectively. Sequences derived from nine other $I$. ricinus ticks had $100 \%$ sequence identity and clustered with the Lyme borreliosis-causing B. burgdorferi and B. afzelii with bootstrap values of $93.4 \%$ and $86.8 \%$ respectively (Fig. 3).

Three $I$. ricinus ticks and 15 I. holocyclus ticks contained sequences from the genus "Candidatus Neoehrlichia" and all $I$. ricinus-derived sequences had $>98 \%$ sequence similarity, and clustered with "Candidatus Neoehrlichia mikurensis" reference sequences (Fig. 4). Ixodes holocyclusderived "Candidatus Neoehrlichia" sequences formed two distinct novel clades with high bootstrap confidence $(94.2 \%$ and $97.2 \%)$ that did not group with any "Candidatus Neoehrlichia" sequences in GenBank (Fig. 4). Sequences within each of these novel "Candidatus Neoehrlichia" clades were less than $1 \%$ dissimilar to each other but more than $6 \%$ dissimilar to any known "Candidatus Neoehrlichia mikurensis" or "Candidatus

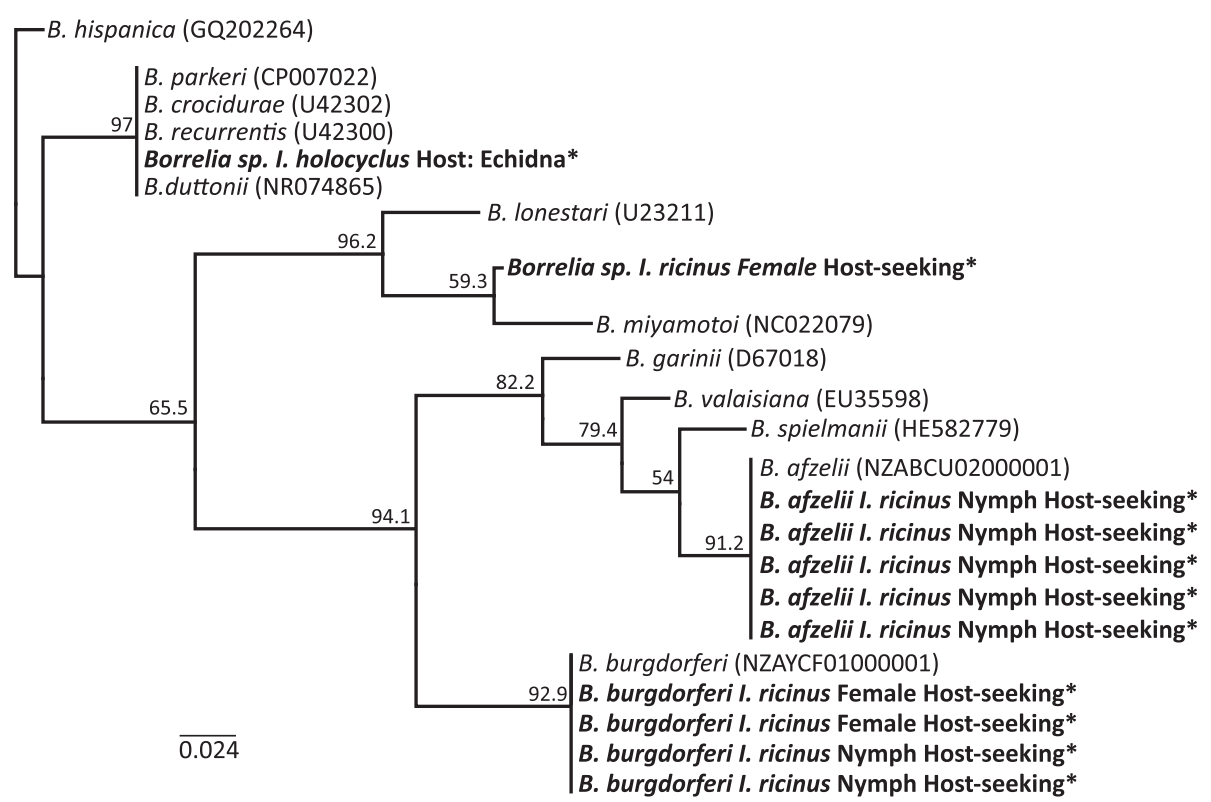

Fig. 3 Neighbour-joining tree of 16S V1-2 Borrelia sequences from I. holocyclus and I. ricinus ticks. Branch labels are bootstrap values inferred from 1000 replicated. Parenthesises after node labels refers to the GenBank accession number. * Indicates sequences from this study 


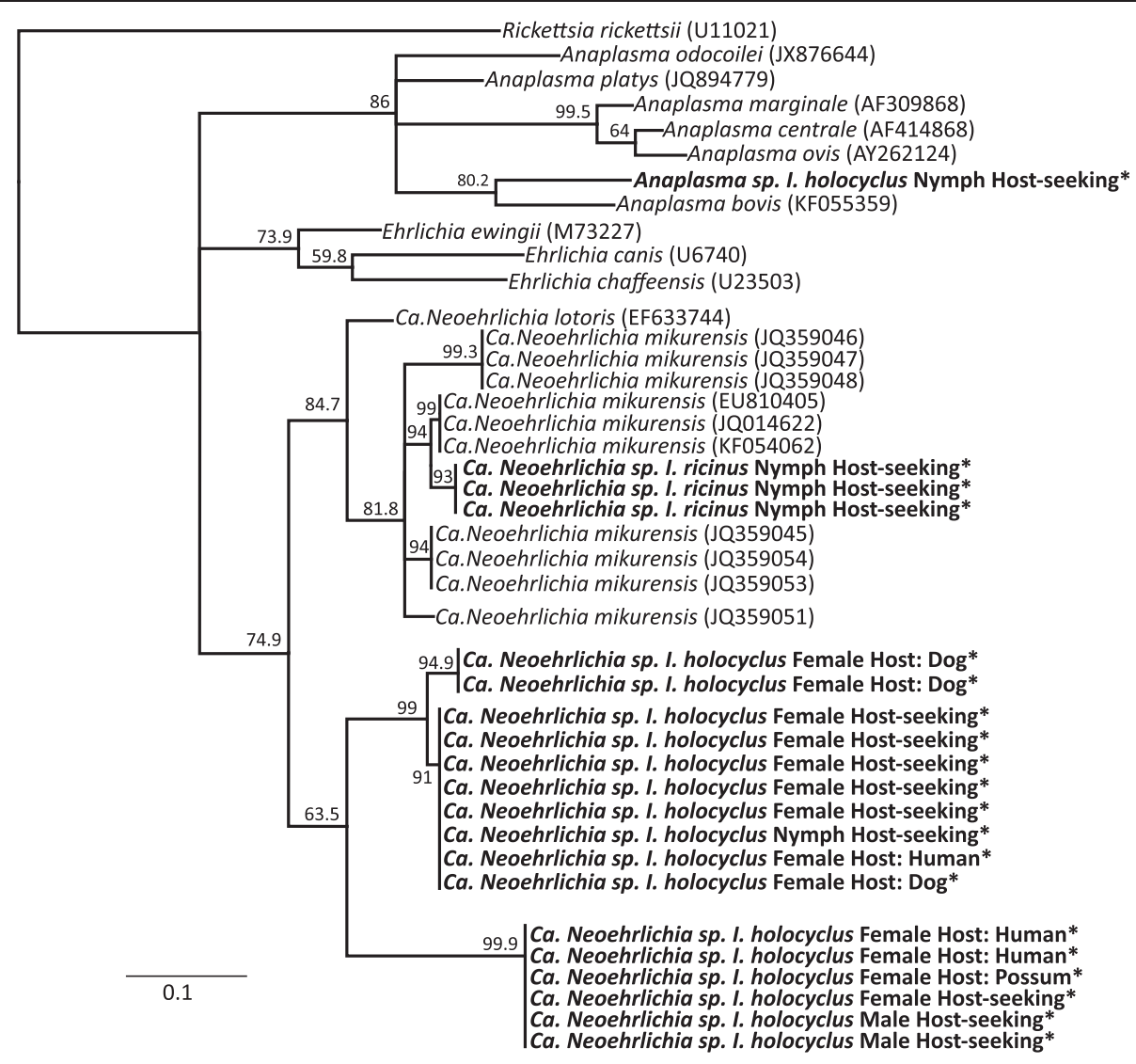

Fig. 4 Neighbour-joining tree of 16S V1-2 "Candidatus Neoehrlichia" sequences from I. holocyclus and I. ricinus ticks. Branch labels are bootstrap values inferred from 1000 replicated. Parenthesises after node labels refers to the GenBank accession number. ${ }^{*}$ Indicates sequences from this study

Neoehrlichia lotoris" $16 \mathrm{~S}$ sequences. One I. holocyclus tick also contained sequences that grouped with relatively high bootstrap confidence (75.1\%) with Anaplasma bovis within a clade that also includes the pathogens $A$. platys, A. Phagocytophilum and A. odocoilei (Fig. 4).

The genus Rickettsia was identified in five I. ricinus ticks and six I. holocyclus ticks. In two I. ricinus ticks, $R$. helvetica was identified with $100 \%$ matches to reference sequences [GenBank: L36212, KJ740388, GQ413963] and no other matches $>97 \%$. Four I. ricinus ticks were infected with Rickettsia spp. that could not be identified to the species level due to high sequence homology (> $99 \%$ ) between many sequences including pathogenic and benign species: one of these ticks was also co-infected with $R$. helvetica. Rickettsia sequences in six I. holocyclus ticks were unable to be resolved to the species level due to high sequence homology (> $99 \%$ ) at the loci sequenced between many Rickettsia spp., including pathogenic and benign species.

The genera Leptospira and Clostridium were identified in 18 and $30 \mathrm{I}$. holocyclus ticks respectively. Leptospira sequences derived from all ticks had $100 \%$ sequence similarity with Leptospira inadai [GenBank: NR115296, AY631891, AY631887] and did not match any other species-specific sequence $>98 \%$. Clostridium sequences from $15 \mathrm{I}$. holocyclus ticks matched with the pathogenic Clostridium histolyticum [GenBank: NR113187, NR104889] with sequence similarity (99.4 \%), however species designation of sequences from the 10 other ticks were unable to be resolved due to high sequence homology (> $99 \%$ ) with between many Clostridium spp.

Bacterial endosymbionts in I. holocyclus and I. ricinus ticks In addition to CMM mentioned previously, the genus Francisella was identified in three questing I. holocyclus nymphs. Francisella sequences from these ticks matched $>98 \%$ with Francisella-like endosymbionts from Amblyomma, Dermacentor, and Ornithodoros ticks, and all sequences were $>6 \%$ dissimilar from the zoonotic pathogen Francisella tularensis. The arthropod endosymbiotic genus Rickettsiella was also identified in eight I. holocyclus ticks and 15 I. ricinus ticks, however speciesspecific discrimination was not possible due to high sequence homology (> $99 \%$ ) between many Rickettsiella 
species at the loci sequenced. The common arthropod endosymbiont Wolbachia was also detected in a single I. holocyclus tick, which matched $>94 \%$ to W. pipientis and other Wolbachia endosymbionts of arthropods.

\section{Discussion}

Blocking primers are a useful tool in molecular microbiology studies, reducing amplification of overabundant sequences that would otherwise dominate sequencing results [70, 81-83]. The application here of a CMMspecific blocking primer significantly reduced the number of CMM sequences in I. ricinus and I. holocyclus samples, allowing identification of previously occult bacteria including other endosymbionts and potential pathogens.

Not unexpectedly, Borrelia burgdorferi and B. afzelii were detected in I. ricinus ticks. The prevalence of these bacteria is high in European tick populations [84] but these Lyme disease-causing agents were not detected in Australian I. holocyclus ticks. However, DNA of a relapsing fever Borrelia sp. was detected in a single I. holocyclus tick from a wild echidna that had $100 \%$ identity to the known relapsing fever pathogens $B$. duttonii, B. recurrentis, $B$. parkeri, and $B$. crocidurae. The significance of this finding is uncertain; Borrelia-like organisms have been suggested in Australia previously $[18,85,86]$ but this is the first report of a relapsing fever Borrelia species in Australia, a finding that may have public health implications. Symptoms of Borrelia relapsing fever can be severe, inducing fevers, myalgia, arthralgia, lethargy, petechial rash, photophobia, and facial palsy.

The organism "Candidatus Neoehrlichia mikurensis" is an emerging tick-borne pathogen that has been detected in rodents, humans, and ticks throughout Europe and Asia [87-90]. A second member of the genus designated "Candidatus Neoehrlichia lotoris" has also been described as a pathogen in the American racoon, Procyon lotor [91]. "Candidatus N. mikurensis" causes significant illness in immunocompromised humans including, but not limited to, anaemia, deep vein thrombosis, fever, diarrhoea, joint and muscle pain, pulmonary embolism, and arterial aneurysm [87-89]. Based on the partial $16 \mathrm{~S}$ sequences reported here, the "Candidatus Neoehrlichia" spp. from I. holocyclus ticks are closely related to, but distinct from, "Candidatus N. mikurensis" and "Candidatus N. lotoris", and may therefore be a novel species. In fact, this is the first description of the "Candidatus Neoehrlichia" genus in Australia; the medical significance of this finding warrants further research to refine its phylogenetic position and investigate its pathogenicity, if any, in humans. Furthermore, the detection of an Anaplasma sp. in one I. holocyclus tick is also of significance, as only two species of Anaplasma have previously been detected in Australia; Anaplasma marginale in Rhipicephalus microplus ticks [92], and Anaplasma platys in $R$. sanguineus ticks in central and northern Australia [93].

Detection of Leptospira inadai during this study may explain the observation over twenty years ago of spirochaete-like objects (SLOs) identified by dark field microscopy of various tick species including I. holocyclus [17]. Although these SLOs were dismissed as aberrant artifacts by the authors, it is noteworthy that the SLOs shown in Figs. 1 and 2 from Russell et al. [17] bear a strong resemblance to various Leptospira spp., including $L$. inadai. Further work isolating and imaging $L$. inadai from $I$. holocyclus is required to confirm this possibility. Recently it was proposed that Leptospira spp. may also be tick-transmitted due to their high prevalence in I. ricinus ticks [94]. Leptospira inadai is pathogenic in laboratory rodents and L. inadai serovar Lyme was isolated from a skin biopsy of a human Lyme disease patient in North America [95]. Although in that case L. inadai was not thought to be associated with the patient's symptoms, its high prevalence in I. holocyclus, and the high prevalence of Leptospira spp. in I. ricinus warrants further investigation.

Francisella-like endosymbionts are well described in Amblyomma and Dermacentor ticks, and have recently been detected in I. ricinus ticks $[28,29,96]$. In this study we report the first instance of a Francisella sp. in the Australian paralysis tick I. holocyclus. Many Francisellalike endosymbionts infect tick species that are also capable of transmitting the zoonotic pathogen Francisella tularensis, making accurate identification by conventional PCR methodologies challenging due to false positive results [97]. The methodology presented here accurately identified non-tularaemia-causing Francisella spp. endosymbiont $16 \mathrm{~S}$ sequences that were $6 \%$ dissimilar from $F$. tularensis reference sequences, indicating that NGS and bioinformatics methodologies may prove useful in clinical diagnostic settings.

\section{Conclusions}

Next-generation $16 \mathrm{~S}$ bacterial profiling is an excellent tool for the simultaneous identification of many bacterial species in arthropods. However, bacterial endosymbionts such as CMM, which are common and abundant in many arthropod vectors such as ticks and mosquitoes, can limit the effectiveness of this method by biasing PCR amplification of less abundant sequences. Here we have shown that a CMM-specific blocking primer significantly increases the amplification and detection of less abundant bacteria including pathogens. Furthermore our CMM-blocking primer is applicable to a range of arthropods that harbour CMM, and can be applied to a wide variety of disease vectors. 
In this study we identified novel candidate pathogens that warrant further scrutiny in the context of investigating so-called "Lyme-like disease" in Australia. Borrelia relapsing fever and "Candidatus Neoehrlichia" pathogens are being identified in new geographic regions throughout the world and their medical importance is well recognised. The aetiological agent of Australian "Lyme-like" illness has been a source of unresolved debate for many years and the discovery of these organisms in Australian I. holocyclus ticks may provide insights into this medical conundrum. Given the widespread presence of endosymbionts in arthropod vectors of disease, together with the fact that such symbionts may be resident in high numbers, our findings also highlight the potential for discovering important novel arthropod-associated bacteria that are in relatively low abundance.

\section{Additional files}

Additional file 1: Cladogram of bacterial genera identified in extraction reagent blank and no-template controls.

Additional file 2: Cladogram of bacterial genera identified in I. holocyclus tick samples after the removal of genera found in control samples. Size of node circle represents the relative abundance of that genus between tick samples on a square-root scale.

Additional file 3: Cladogram of bacterial genera identified in I. ricinus tick samples after the removal of genera found in control samples. Size of node circle represents the relative abundance of that genus between tick samples on a square-root scale.

Competing interests

The authors declare that they have no competing interests

\section{Authors' contributions}

AWG performed DNA extractions, tick identification, $16 \mathrm{~S}$ library preparations, next-generation sequencing, data analysis, drafted the manuscript and participated in the design of the study. CLO contributed to data analysis, the design of the study, and preparation of the manuscript. NL contributed to conceiving, designing and coordinating the study, tick collection and identification, and preparation of the manuscript. TB, HW, and WW contributed to tick collections and identification, and DNA extractions. DM and AP contributed to data analysis and preparation of the manuscript. TLG contributed to DNA extractions, tick identification, and preparation of the manuscript. $A H, M B$, and UR contributed to the design of the study and preparation of the manuscript. PI conceived, designed and coordinated the study and contributed to preparation of the manuscript. All authors read and approved the final manuscript.

\section{Acknowledgements}

This study was part-funded by the Australian Research Council (LP13010005), Bayer HealthCare (Germany) and Bayer Australia. The authors wish to acknowledge the assistance of Reinhard Straubinger and Martin Pfeffer for the collection of Ixodes ricinus ticks in Germany; Andrew Ratchford for the collection of ticks from humans; and Stephen Doggett for the identification of specimens of I. holocyclus. We thank Lyn McDougall, Derek Spielman, Mark Krockenberger, Joanna Griffith, Simon Craig, Graeme Brown, Kathryn Schlotfeldt, Lindsay Kemp, Craig Coorey, and veterinary clinicians from the following clinics for providing and curating tick samples from wildlife: Merewether Veterinary Specialist Centre, Wauchope Veterinary Clinic, Gordon Veterinary Hospital, Snowy River Veterinary Clinic, Asquith Veterinary Clinic, and Salamander Bay Veterinary Clinic.

\section{Author details}

'Vector and Water-Borne Pathogen Research Laboratory, School of Veterinary and Life Sciences, Murdoch University, Perth, Western Australia, Australia. ${ }^{2}$ School of Biological Sciences, The University of Sydney, Sydney, New South Wales, Australia. ${ }^{3}$ Faculty of Veterinary Science, The University of Sydney, Sydney, New South Wales, Australia. ${ }^{4}$ Trace and Environmental DNA Laboratory, Department of Environment and Agriculture, Curtin University, Perth, Western Australia, Australia. ${ }^{5}$ School of Molecular Biosciences and Charles Perkins Centre, The University of Sydney, Sydney, New South Wales, Australia.

Received: 5 May 2015 Accepted: 17 June 2015

Published online: 25 June 2015

\section{References}

1. Dantas-Torres F, Chomel BB, Otranto D. Ticks and tick-borne diseases: a One health perspective. Trends Parasitol. 2012;28(10):437-46.

2. Githeko AK, Lindsay SW, Confalonieri UE, Patz JA. Climate change and vector-borne diseases: a regional analysis. Bull World Health Organ. 2000;78(9):1136-47.

3. Parola P, Raoult D. Ticks and tickborne bacterial diseases in humans: an emerging infectious threat. Clin Infect Dis. 2001;32(6):897-928.

4. Hartelt K, Oehme R, Frank H, Brockmann SO, Hassler D, Kimmig P. Pathogens and symbionts in ticks: prevalence of Anaplasma phagocytophilum (Ehrlichia sp.), Wolbachia sp., Rickettsia sp., and Babesia sp. in Southern Germany. Intl J Med Microbio Sup. 2004:293(37):86-92

5. Sanogo YO, Zeaiter Z, Caruso G, Merola F, Shpynov S, Brouqui P, et al. Bartonella henselae in ixodes ricinus ticks (acari: ixodida) removed from humans, belluno province. Italy Emerg Infect Dis. 2003;9(3):329-32.

6. Burgdorfer W, Lane RS, Barbour AG, Gresbrink RA, Anderson JR. The western black-legged tick, Ixodes pacificus: a vector of Borrelia burgdorferi. Am J Trop Med Hyg. 1985;34(5):925-30.

7. Dumler JS, Bakken JS. Ehrlichial diseases of humans: emerging tick-borne infections. Clin Infect Dis. 1995;20(5):1102-10.

8. Petersen JM, Mead PS, Schriefer ME. Francisella tularensis: an arthropodborne pathogen. Vet Res. 2009;40(2):07.

9. Azad AF, Beard CB. Rickettsial pathogens and their arthropod vectors. Emerg Infect Dis. 1998;4(2):179-86.

10. Richter D, Matuschka F-R. "Candidatus Neoehrlichia mikurensis", Anaplasma phagocytophilum and Lyme disease spirochetes in questing European vector ticks and in feeding ticks removed from people. J Clin Microbiol. 2011;JCM:05802-11

11. Colwell DD, Dantas-Torres F, Otranto D. Vector-borne parasitic zoonoses: emerging scenarios and new perspectives. Vet Parasitol. 2011;182(1):14-21.

12. Shaw SE, Day MJ, Birtles RJ, Breitschwerdt EB. Tick-borne infectious diseases of dogs. Trends Parasitol. 2001;17(2):74-80.

13. Welc-Faleciak R, Hildebrandt A, Sinski E. Co-infection with Borrelia species and other tick-borne pathogens in humans: two cases from Poland. Ann Agric Environ Med. 2010;17(2):309-13.

14. Hofhuis A, Harms M, van den Wijngaard C, Sprong H, van Pelt W. Continuing increase of tick bites and Lyme disease between 1994 and 2009. Ticks Tick-Borne Dis. 2015;6(1):69-74.

15. Stewart A, Glass J, Patel A, Watt G, Cripps A, Clancy R. Lyme arthritis in the hunter valley. Med J Aust. 1982;1(3):139.

16. Russell R. Vectors vs. Humans in Australia-who is on top down under? an update on vector-borne disease and research on vectors in Australia. J Vector Ecol. 1998;23(1):1-46.

17. Russell RC, Doggett SL, Munro R, Ellis J, Avery D, Hunt C, et al. Lyme disease: a search for a causative agent in ticks in south-eastern Australia. Epidemiol Infect. 1994;112(2):375-84.

18. Wills MC, Barry RD. Detecting the cause of Lyme disease in Australia. Med Aust. 1991;155(4):275

19. Mayne PJ. Emerging incidence of Lyme borreliosis, babesiosis, bartonellosis, and granulocytic ehrlichiosis in Australia. Int J Gen Med. 2011;4:845-52.

20. Barker SC, Walker AR, Campelo D. A list of the 70 species of Australian ticks: diagnostic guides to and species accounts of Ixodes holocyclus (paralysis tick), Ixodes cornuatus (southern paralysis tick) and Rhipicephalus australis (Australian cattle tick); and consideration of the place of Australia in the evolution of ticks with comments on four controversial ideas. Int J Parasitol. 2014;44(12):941-53. 
21. Barker SC, Walker AR. Ticks of Australia. The species that infest domestic animals and humans. Zootaxa. 2014;3816:1-144.

22. Song S, Shao R, Atwell R, Barker S, Vankan D. Phylogenetic and phylogeogra.phic relationships in Ixodes holocyclus and Ixodes comuatus (Acari: Ixodidae) inferred from COX1 and ITS2 sequences. Int J Parasitol. 2011;41(8):871-80

23. Campbell RW, Domrow R. Rickettsioses in Australia: isolation of Rickettsia tsutsugamushi and R. australis from naturally infected arthropods. Trans $\mathrm{R}$ Soc Trop Med Hyg. 1974;68(5):397-402.

24. Klyachko O, Stein BD, Grindle N, Clay K, Fuqua C. Localization and visualization of a coxiella-type symbiont within the lone star tick. Amblyomma americanum. Appl Environ Microbiol. 2007;73(20):6584-94.

25. Lalzar I, Harrus S, Mumcuoglu KY, Gottlieb Y. Composition and seasonal variation of Rhipicephalus turanicus and Rhipicephalus sanguineus bacterial communities. Appl Environ Microbiol. 2012;78(12):4110-6.

26. Liu L, Li L, Liu J, Hu Y, Liu Z, Guo L, et al. Coinfection of Dermacentor silvarum olenev (acari: Ixodidae) by Coxiella-Like, Arsenophonus-like, and Rickettsia-like symbionts. Appl Environ Microbiol. 2013;79(7):2450-4.

27. Scoles GA. Phylogenetic analysis of the Francisella-like endosymbionts of Dermacentor ticks. J Med Entomol. 2004;41(3):277-86.

28. Sun LV, Scoles GA, Fish D, O'Neill SL. Francisella-like endosymbionts of ticks. J Invertebr Pathol. 2000;76(4):301-3.

29. Venzal JM, Estrada-Peña A, Castro O, de Souza CG, Félix ML, Nava S, et al. Amblyomma triste Koch, 1844 (Acari: Ixodidae): hosts and seasonality of the vector of Rickettsia parkeri in Uruguay. Vet Parasitol. 2008;155(1-2):104-9.

30. Andreotti R, de León AAP, Dowd SE, Guerrero FD, Bendele KG, Scoles GA. Assessment of bacterial diversity in the cattle tick Rhipicephalus (Boophilus) microplus through tag-encoded pyrosequencing. BMC Microbiol. 2011:11(1):6

31. Benson MJ, Gawronski JD, Eveleigh DE, Benson DR. Intracellular symbionts and other bacteria associated with deer ticks (ixodes scapularis) from Nantucket and Wellfleet, cape Cod. Massachusetts. Appl Environ Microbiol. 2004;70(1):616-20

32. Hirunkanokpun S, Kittayapong P, Cornet J-P, Gonzalez J-P. Molecular evidence for novel tick-associated spotted fever group rickettsiae from Thailand. J Med Entomol. 2003:40(2):230-7.

33. Niebylski ML, Schrumpf ME, Burgdorfer W, Fischer ER, Gage KL, Schwan TG. Rickettsia peacockii sp. nov., a New species infecting wood ticks, dermacentor andersoni, in western Montana. Int J Syst Bacteriol. 1997;47(2):446-52.

34. Reis C, Cote M, Paul REL, Bonnet S. Questing ticks in suburban forest are infected by at least six tick-borne pathogens. Vector Borne Zoonotic Dis. 2011;11(7):907-16.

35. Satta G, Chisu V, Cabras P, Fois F, Masala G. Pathogens and symbionts in ticks: a survey on tick species distribution and presence of tick-transmitted micro-organisms in Sardinia, Italy. J Med Microbiol. 2011;60(1):63-8.

36. Sassera D, Beninati T, Bandi C, Bouman EAP, Sacchi L, Fabbi M, et al. "Candidatus Midichloria mitochondrii", an endosymbiont of the tick Ixodes ricinus with a unique intramitochondrial lifestyle. Int J Syst Evol Microbiol. 2006:56(11):2535-40.

37. Beninati T, Riegler M, Vilcins I-ME, Sacchi L, McFadyen R, Krockenberger M, et al. Absence of the symbiont "Candidatus Midichloria mitochondrii" in the mitochondria of the tick Ixodes holocyclus. FEMS Microbiol Lett. 2009;299(2):241-7

38. Harrus S, Perlman-Avrahami A, Mumcuoglu KY, Morick D, Eyal O, Baneth G. Molecular detection of Ehrlichia canis, Anaplasma bovis, Anaplasma platys, Candidatus Midichloria mitochondrii and Babesia canis vogeli in ticks from Israel. Clin Microbiol Infect. 2011;17(3):459-63.

39. Williams-Newkirk AJ, Rowe LA, Mixson-Hayden TR, Dasch GA. Presence, genetic variability, and potential significance of "Candidatus Midichloria mitochondrii" in the lone star tick Amblyomma americanum. Exp Appl Acarol. 2012;58(3):291-300.

40. Ahantarig A, Trinachartvanit W, Baimai V, Grubhoffer L. Hard ticks and their bacterial endosymbionts (or would be pathogens). Folia Microbiol (Praha). 2013;58(5):419-28.

41. Haine ER. Symbiont-mediated protection. Proc Biol Sci. 2008;275(1633):353-61.

42. Walker $\mathrm{T}$, Johnson PH, Moreira LA, Iturbe-Ormaetxe I, Frentiu FD, McMeniman CJ, et al. The wMel Wolbachia strain blocks dengue and invades caged Aedes aegypti populations. Nature. 2011;476(7361):450-3.

43. Epis S, Sassera D, Beninati T, Lo N, Beati L, Piesman J, et al. Midichloria mitochondrii is widespread in hard ticks (Ixodidae) and resides in the mitochondria of phylogenetically diverse species. Parasitology. 2008:135(4):485-94

44. Dergousoff SJ, Chilton NB. Novel genotypes of Anaplasma bovis, "Candidatus Midichloria" sp. and Ignatzschineria sp. in the Rocky Mountain wood tick, Dermacentor andersoni. Vet Microbiol. 2011;150(1-2):100-6.

45. Montagna M, Sassera D, Epis S, Bazzocchi C, Vannini C, Lo N, et al. "Candidatus Midichloriaceae" fam. nov. (Rickettsiales), an ecologically widespread clade of intracellular alphaproteobacteria. Appl Environ Microbiol. 2013;79(10):3241-8.

46. Granquist EG, Kristiansson M, Lindgren P-E, Matussek A, Nødtvedt A, Okstad W, et al. Evaluation of microbial communities and symbionts in Ixodes ricinus and ungulate hosts (Cervus elaphus and Ovis aries) from shared habitats on the west coast of Norway. Ticks Tick Borne Dis. 2014;5(6):780-4.

47. Williams-Newkirk AJ, Rowe LA, Mixson-Hayden TR, Dasch GA. Characterization of the bacterial communities of life stages of free living lone star ticks (amblyomma americanum). PLoS One. 2014;9(7):e102130.

48. Hornok S, Földvári G, Elek V, Naranjo V, Farkas R, de la Fuente J. Molecular identification of Anaplasma marginale and rickettsial endosymbionts in blood-sucking flies (Diptera: Tabanidae, Muscidae) and hard ticks (Acari: Ixodidae). Vet Parasitol. 2008;154(3-4):354-9.

49. Richard S, Seng P, Parola P, Raoult D, Davoust B, Brouqui P. Detection of a new bacterium related to "Candidatus Midichloria mitochondrii" in bed bugs. Clin Microbiol Infect. 2009;15:84-5.

50. Reeves WK, Dowling APG, Dasch GA. Rickettsial agents from parasitic dermanyssoidea (Acari: Mesostigmata). Exp Appl Acarol. 2006;38(2-3):181-8.

51. Lo N, Beninati T, Sassera D, Bouman EA, Santagati S, Gern L, et al. Widespread distribution and high prevalence of an alpha-proteobacterial symbiont in the tick Ixodes ricinus. Environ Microbiol. 2006;8(7):1280-7.

52. Mariconti M, Epis S, Gaibani P, Valle CD, Sassera D, Tomao P, et al. Humans parasitized by the hard tick /xodes ricinus are seropositive to Midichloria mitochondrii: Is Midichloria a novel pathogen, or just a marker of tick bite? Pathogens Global Health. 2012;106(7):391-6.

53. Skarphédinsson S, Jensen PM, Kristiansen K. Survey of tickborne infections in Denmark. Emerging Infect Dis. 2005;11(7):1055-61.

54. Carpi G, Cagnacci F, Wittekindt NE, Zhao F, Qi J, Tomsho LP, et al. Metagenomic profile of the bacterial communities associated with ixodes ricinus ticks. Plos One. 2011;6(10):e25604.

55. Melničáková J, Derdáková M, Barák I. A system to simultaneously detect tickborne pathogens based on the variability of the $16 \mathrm{~S}$ ribosomal genes. Parasit Vectors. 2013:6:269.

56. Menchaca AC, Visi DK, Strey OF, Teel PD, Kalinowski K, Allen MS, et al. Preliminary Assessment of Microbiome Changes Following Blood-Feeding and Survivorship in the Amblyomma americanum Nymph-to-Adult Transition using Semiconductor Sequencing. PLoS ONE. 2013;8(6).

57. Nakao R, Abe T, Nijhof AM, Yamamoto S, Jongejan F, Ikemura T, et al. A novel approach, based on BLSOMs (Batch Learning Self-Organizing Maps), to the microbiome analysis of ticks. ISME J. 2013;7(5):1003-15.

58. Bonnet S, Michelet L, Moutailler S, Cheval J, Hébert C, Vayssier-Taussat M et al. Identification of parasitic communities within European ticks using next-generation sequencing. PLoS Negl Trop Dis. 2014;8(3):e2753.

59. Budachetri K, Browning RE, Adamson SW, Dowd SE, Chao C-C, Ching W-M, et al. An insight into the Microbiome of the Amblyomma maculatum (Acari: Ixodidae). J Med Entomol. 2014;51(1):119-29.

60. Ponnusamy L, Gonzalez A, Van Treuren W, Weiss S, Parobek CM, Juliano JJ, et al. Diversity of rickettsiales in the microbiome of the lone star tick, Amblyomma americanum. Appl Environ Microbiol. 2014;80(1):354-9.

61. Zhang X-C, Yang Z-N, Lu B, Ma X-F, Zhang C-X, Xu H-J. The composition and transmission of microbiome in hard tick, Ixodes persulcatus, during blood meal. Ticks Tick Borne Dis. 2014;5(6):864-70.

62. Vayssier-Taussat M, Moutailler S, Michelet L, Devillers E, Bonnet S, Cheval J, et al. Next generation sequencing uncovers unexpected bacterial pathogens in ticks in western Europe. PLoS One. 2013;8(11):e81439.

63. Lane DJ, Pace B, Olsen GJ, Stahl DA, Sogin ML, Pace NR. Rapid determination of $16 \mathrm{~S}$ ribosomal RNA sequences for phylogenetic analyses. PNAS. 1985;82(20):6955-9.

64. Liu Z, DeSantis TZ, Andersen GL, Knight R. Accurate taxonomy assignments from 165 rRNA sequences produced by highly parallel pyrosequencers. Nucl Acids Res. 2008;36(18):e120.

65. Klappenbach JA, Dunbar JM, Schmidt TM. rRNA operon copy number reflects ecological strategies of bacteria. Appl Environ Microbiol. 2000;66(4):1328-33. 
66. Větrovský $T$, Baldrian $P$. The variability of the 165 rRNA gene in bacterial genomes and its consequences for bacterial community analyses. PLoS One. 2013;8(2):e57923.

67. Jensen PM. Host seeking activity of ixodes ricinus ticks based on daily consecutive flagging samples. Exp Appl Acarol. 2000;24(9):695-708.

68. Arthur DR. British ticks. London: Butterworths; 1963.

69. Roberts FHS. Australian ticks. Melbourne: Commonwealth Scientific and Industrial Research Organisiation; 1970.

70. Vestheim $H$, Jarman SN. Blocking primers to enhance PCR amplification of rare sequences in mixed samples - a case study on prey DNA in Antarctic krill stomachs. Front Zoology. 2008;5(1):12.

71. Turner S, Pryer KM, Miao VPW, Palmer JD. Investigating deep phylogenetic relationships among cyanobacteria and plastids by small subunit rRNA sequence Analysis1. J Eukaryot Microbiol. 1999;46(4):327-38.

72. Caporaso JG, Kuczynski J, Stombaugh J, Bittinger K, Bushman FD, Costello EK, et al. QIIME allows analysis of high-throughput community sequencing data. Nat Meth. 2010;7(5):335-6.

73. Chakravorty S, Helb D, Burday M, Connell N, Alland D. A detailed analysis of 165 ribosomal RNA gene segments for the diagnosis of pathogenic bacteria. J Microbiol Methods. 2007;69(2):330-9.

74. Kearse M, Moir R, Wilson A, Stones-Havas S, Cheung M, Sturrock S, et al. Geneious Basic: an integrated and extendable desktop software platform for the organization and analysis of sequence data. Bioinformatics. 2012;28(12):1647-9.

75. Edgar RC. Search and clustering orders of magnitude faster than BLAST. Bioinformatics. 2010;26(19):2460-1.

76. Edgar RC. UPARSE: highly accurate OTU sequences from microbial amplicon reads. Nat Meth. 2013;10(10):996-8.

77. Edgar RC, Haas BJ, Clemente JC, Quince C, Knight R. UCHIME improves sensitivity and speed of chimera detection. Bioinformatics. 2011;27(16):2194-200

78. DeSantis TZ, Hugenholtz P, Larsen N, Rojas M, Brodie EL, Keller K, et al. Greengenes, a chimera-checked 16S rRNA gene database and workbench compatible with ARB. Appl Environ Microbiol. 2006;72(7):5069-72.

79. Altschul SF, Gish W, Miller W, Myers EW, Lipman DJ. Basic local alignment search tool. J Mol Biol. 1990;215(3):403-10.

80. Edgar RC. MUSCLE: a multiple sequence alignment method with reduced time and space complexity. BMC Bioinformatics. 2004;5(1):113.

81. Boessenkool S, Epp LS, Haile J, Bellemain E, Edwards M, Coissac E, et al. Blocking human contaminant DNA during PCR allows amplification of rare mammal species from sedimentary ancient DNA. Mol Ecol. 2012;21(8):1806-15.

82. Khanna M, Park P, Zirvi M, Cao W, Picon A, Day J, et al. Multiplex PCR/LDR for detection of K-ras mutations in primary colon tumors. Oncogene. 1999;18(1):27-38.

83. Liles MR, Manske BF, Bintrim SB, Handelsman J, Goodman RM. A census of rRNA genes and linked genomic sequences within a soil metagenomic library. Appl Environ Microbiol. 2003;69(5):2684-91.

84. Rauter C, Hartung T. Prevalence of Borrelia burgdorferi sensu lato genospecies in Ixodes ricinus ticks in Europe: a metaanalysis. Appl Environ Microbiol. 2005;71(11):7203-16.

85. Carley JG, Pope JH. A new species of Borrelia (B. queenslandica) from Rattus villosissimus in Queensland. Aust J Exp Biol Med Sci. 1962;40:255-61.

86. Mackerras M. The haematozoa of Australian mammals. Aust J Zoo. 1959;7(2):105-35.

87. Pekova S, Vydra J, Kabickova H, Frankova S, Haugvicova R, Mazal O, et al. Candidatus Neoehrlichia mikurensis infection identified in 2 hematooncologic patients: benefit of molecular techniques for rare pathogen detection. Diagn Microbiol Infect Dis. 2011;69(3):266-70.

88. Grankvist A, Andersson P-O, Mattsson M, Sender M, Vaht K, Höper L, et al. Infections with the tick-borne bacterium "Candidatus Neoehrlichia mikurensis" mimic non-infectious conditions in patients with B cell malignancies or autoimmune diseases. Clin Infect Dis. 2014;18:ciu189.

89. Li H, Jiang J-F, Liu W, Zheng Y-C, Huo Q-B, Tang K, et al. Human Infection with Candidatus Neoehrlichia mikurensis. China Emerg Infect Dis. 2012;18(10):1636-9.

90. Obiegala A, Pfeffer M, Pfister K, Tiedemann T, Thiel C, Balling A, et al. Candidatus Neoehrlichia mikurensis and Anaplasma phagocytophilum: prevalences and investigations on a new transmission path in small mammals and ixodid ticks. Parasites \& Vectors. 2014;7(1):563.
91. Yabsley MJ, Murphy SM, Luttrell MP, Wilcox BR, Howerth EW, Munderloh UG. Characterization of "Candidatus Neoehrlichia lotoris" (family Anaplasmataceae) from raccoons (Procyon lotor). Int J Syst Evol Microbiol. 2008;58(0 12):2794-8.

92. Graves S, Unsworth N, Stenos J. Rickettsioses in Australia. Ann N Y Acad Sci. 2006;1078:74-9.

93. Brown GK, Canfield PJ, Dunstan RH, Roberts TK, Martin AR, Brown CS, et al. Detection of Anaplasma platys and Babesia canis vogeli and their impact on platelet numbers in free-roaming dogs associated with remote Aboriginal communities in Australia. Aust Vet J. 2006;84(9):321-5.

94. Wójcik-Fatla A, Zając V, Cisak E, Sroka J, Sawczyn A, Dutkiewicz J. Leptospirosis as a tick-borne disease? detection of leptospira spp. In ixodes ricinus ticks in eastern Poland. Ann Agric Environ Med. 2012;19(4):656-9.

95. Schmid GP, Steere AC, Kornblatt AN, Kaufmann AF, Moss CW, Johnson RC, et al. Newly recognized Leptospira species ("Leptospira inadai" serovar lyme) isolated from human skin. J Clin Microbiol. 1986;24(3):484-6.

96. Wójcik-Fatla A, Zając V, Sawczyn A, Cisak E, Sroka J, Dutkiewicz J. Occurrence of Francisella spp. in Dermacentor reticulatus and Ixodes ricinus ticks collected in eastern Poland. Ticks Tick Borne Dis. 2015;6(3):253-7.

97. Kugeler KJ, Gurfield N, Creek JG, Mahoney KS, Versage JL, Petersen JM. Discrimination between Francisella tularensis and Francisella-Like Endosymbionts when screening ticks by PCR. Appl Environ Microbiol. 2005;71(11):7594-7.

\section{Submit your next manuscript to BioMed Central and take full advantage of:}

- Convenient online submission

- Thorough peer review

- No space constraints or color figure charges

- Immediate publication on acceptance

- Inclusion in PubMed, CAS, Scopus and Google Scholar

- Research which is freely available for redistribution 